\title{
Utilização de métodos físicos e de fitorreguladores para superação de dormência em sementes de pinha
}

\author{
Luís Henrique Costa Vasconcelos ${ }^{1}$, Eduardo Pradi Vendruscolo ${ }^{1}$, Rebeca Freitas \\ Vasconcelos $^{1}$, Marivone Moreira dos Santos ${ }^{1}$, Alexsander Seleguini ${ }^{1}$ \\ ${ }^{1}$ Universidade Federal de Goiás/UFG, Goiânia, Goiás, Brasil. E-mail: luishcvasconcelos@gmail.com, rebeca.eng@gmail.com, \\ aseleguini@gmail.com, eduardopradi@gmail.com, marivone.santos@uol.com.br
}

Recebido: 22/07/2015; Aceito: 27/11/2015.

\section{RESUMO}

A pinha é uma fruta muito apreciada devido ao sabor, e pode ser propagada por sementes ou de forma vegetativa por enxertia. No entanto, a produção de mudas por propagação seminal é dificultada pela dormência acentuada das sementes. Neste aspecto, objetivou-se determinar o melhor tratamento para a superação de dormência de sementes de pinha (Annona squamosa L.), submetendo-as à associação de tratamento pré-germinativo mecânico e não mecânico. Foi empregado o delineamento experimental inteiramente casualizado em esquema fatorial $4 \times 2$, com quatro repetições. Os tratamentos foram caracterizados por quatros tratamentos pré-germinativos não mecânicos em associação a tratamento pré-germinativo mecânico (presença ou ausência) com escarificação mecânica com lixa $\mathrm{n}^{\circ}$ 120. Os tratamentos avaliados foram: T1 - Controle sem escarificação; T2 - Escarificação mecânica; T3 - Ethrel $\left(500 \mathrm{mg} \mathrm{L}^{-1}\right)$; $\mathrm{T} 4$ - Ethrel $\left(500 \mathrm{mg} \mathrm{L}^{-1}\right)+$ escarificação mecânica; $\mathrm{T} 5$ - Água quente $\left(60{ }^{\circ} \mathrm{C}\right.$ por 1 minuto); T6 Água quente $\left(60^{\circ} \mathrm{C}\right.$ por 1 minuto) + escarificação mecânica; T7 - Ácido giberélico, GA3 $\left(1000 \mathrm{mg} \mathrm{L}^{-1}\right)$; T8 - Ácido giberélico, GA $3\left(1000 \mathrm{mg} \mathrm{L}^{-1}\right)$ + escarificação mecânica. Avaliou-se a taxa de germinação, tempo, índice e velocidade de germinação, além do comprimento da raiz primária. Os tratamentos pré-germinativos das sementes de pinha com ácido giberélico em associação com escarificação mecânica tornaram-se os métodos mais indicados para a superação da dormência desta espécie.

Palavras-chave: Annona squamosa L., fitormônios, reguladores vegetais, escarificação, anonáceas.

\section{Use of chemical and physical methods for dormancy overcoming in custard apple seeds}

\section{ABSTRACT}

The custard apple is a very popular fruit because of the flavor, and can be propagated by seed or grafting. However, the production of seedlings per seed propagation is hindered by the strong seed dormancy. The objective was to determine the best treatment for overcoming pine cone seed dormancy (Annona squamosa L.), submitting them to pregerminative mechanical and non-mechanical combination treatment. The completely randomized design in $4 \times 2$ factorial arrangement with four replicates were used. Treatments consisted of four pre-germination treatments not mechanical in combination with mechanical pre-germination treatment (presence or absence) with mechanical scarification with sandpaper. The treatments were: $\mathrm{T} 1$ - control without scarification; $\mathrm{T} 2$ - mechanical scarification; $\mathrm{T} 3$ - Ethrel $\left(500 \mathrm{mg} \mathrm{L}^{-1}\right)$; $\mathrm{T} 4$ - Ethrel $\left(500 \mathrm{mg} \mathrm{L}^{-1}\right)+$ mechanical scarification; $\mathrm{T} 5$ - hot water $\left(60{ }^{\circ} \mathrm{C}\right.$ for 1 minute); $\mathrm{T} 6$ - hot water $\left(60{ }^{\circ} \mathrm{C}\right.$ for 1 minute $)+$ mechanical scarification; $\mathrm{T} 7$ - gibberellic acid, $\mathrm{GA}_{3}\left(1000 \mathrm{mg} \mathrm{L}^{-1}\right)$; $\mathrm{T} 8$ gibberellic acid, GA $3\left(1000 \mathrm{mg} \mathrm{L}^{-1}\right)+$ mechanical scarification. The germination, time, index and germination rate, and length of primary root were measured. The pre-germination treatments of pine cone seeds with gibberellic acid in combination with mechanical scarification is the preferred method for breaking dormancy of this species.

Key words: Annona squamosa L., phytormones, plant growth regulator, scarification, Annonaceae. 


\section{Introdução}

A fruticultura é um setor econômico que vem desenvolvendo-se em todo o Brasil, fornecendo produtos para consumo interno e para a exportação. Neste panorama, encontram-se as Anonáceas, que compreendem um grande número de gêneros e espécies, maior parte, nativas das regiões tropicais ou subtropicais (SILVA et al., 2009; NETO et al., 2014). Diversas espécies despertam interesse como frutíferas comerciais, sendo exploradas e cultivadas em vários países. No Brasil, é acentuado e relevante o interesse da produção dessas frutas, principalmente, a pinha (Annona squamosa L.) (FERREIRA et al., 2009).

A pinha também conhecida como fruta-do-conde ou ata, é muito cultivada no Brasil, desenvolvendo-se bem em regiões de clima quente (BRAGA SOBRINHO, 2014; SÃO JOSÉ et al., 2014). A polpa do fruto é perfumada, doce e de sabor agradável. Na produção comercial de mudas há interesse tanto na uniformidade como na porcentagem de sementes germinadas. Para algumas espécies a superação da dormência constitui fator de importância na germinação das sementes e no estabelecimento das plântulas (GALINDO et al., 2012).

Para às Anonáceas, a forma mais indicada de propagação, dá-se via enxertia, sendo que as sementes são utilizadas para o porta-enxerto (SCALOPPI JUNIOR; MARTINS, 2014). Entretanto, suas sementes contêm substâncias que possuem efeito inibidor de germinação, provocando consequentemente, dormência, que somada à impermeabilidade e resistência do tegumento, proporcionam fatores antagônicos à germinação uniforme e rápida (STENZEL et al., 2003).

$\mathrm{O}$ entendimento e o conhecimento do mecanismo de dormência e da superação da dormência em sementes são fatores relevantes no processo de produção de mudas (SILVA et al., 2011). Embora o fenômeno da dormência em sementes de pinha já tenha sido explorado e comprovado, as fases que sucedem a germinação são pouco conhecidas, entre elas os mecanismos moleculares e fisiológicos do sinergismo com a indução, manutenção e superação da dormência.

Resultados positivos de superação da dormência de sementes Anonáceas foram observados por Campos et al. (2015), que estudaram a combinação de escarificação física e doses de ácido giberélico em tratamento pré-germinativo de biribá. Os autores observaram aumento significativo das variáveis germinativas e de crescimento inicial quando a escarificação física é utilizada conjuntamente com doses crescentes de $\mathrm{GA}_{3}$ até $1000 \mathrm{mg} \mathrm{L}^{-1}$.

Outro agente com potencial para utilização na superação da dormência de sementes é o etefon. No entanto, as informações sobre seu uso para este fim são escassas e seus efeitos podem variar de acordo com a espécie estudada. Melo et al (2012) observaram que a utilização do produto comercial Ethrel (100 $\left.\mathrm{mg} \mathrm{L}^{-1}\right)$ proporciona incrementos na velocidade de emergência e no desenvolvimento do sistema radicular de umbuzeiro.

Há muito interesse na produção de gêneros Anonáceas entre as frutíferas comerciais principais, fato que denota a relevância de novos estudos que associem a superação da dormência de sementes por meios físicos e químicos para um real avanço da produção (MENEGAZZO et al., 2013).

Devido à importância e ao potencial dos frutos da família das anonáceas, objetivou-se determinar o melhor tratamento para a superação de dormência de sementes de pinha (Annona squamosa L.), submetendo-as à associação de tratamento prégerminativo mecânico e não mecânico.

\section{Material e Métodos}

Os frutos foram colhidos em produções regularizadas e adquiridos no mercado do produtor, localizado em Anápolis - Goiás entre os meses de março e abril de 2015. Os frutos foram selecionados de forma manual observando a uniformidade do estágio de maturação - com frutos de vez - e o completo desenvolvimento fisiológico e ausência de defeitos; frutos em potencial consumo comercial.

Foi empregado o delineamento experimental inteiramente casualizado, em esquema fatorial $4 \times 2$, caracterizado por quatros tratamentos pré-germinativos não mecânicos em associação a tratamento prégerminativo mecânico (presença ou ausência) com escarificação mecânica utilizando lixa $n^{\circ} 120$, a qual deu origem aos tratamentos assim compostos: T1 Controle sem escarificação; T2 - Escarificação mecânica; T3 - Ethrel (500 mg L $\left.{ }^{-1}\right)$; T4 - Ethrel (500 $\left.\mathrm{mg} \mathrm{L} \mathrm{L}^{-1}\right)$ + escarificação mecânica; T5 - Água quente $\left(60^{\circ} \mathrm{C}\right.$ por 1 minuto); T6 - Água quente $\left(60^{\circ} \mathrm{C}\right.$ por 1 minuto) + escarificação mecânica; T7 - Ácido giberélico, GA3 (1000 mg L ${ }^{-1}$ ); T8 - Ácido giberélico, GA $3\left(1000 \mathrm{mg} \mathrm{L}^{-1}\right)+$ escarificação mecânica. Cada tratamento foi composto por quatro repetições. A escarificação mecânica consistiu na fricção vigorosa do tegumento das sementes próxima a região de brotação.

Os tratamentos com Ethrel com e sem escarificação mecânica, foi representado pela concentração do fitoregulador Etefom (ácido 2-cloroetilfosfônico, produto comercial Ethrel a $24 \%$ i.a., princípio ativo etefom), diluído em água, adotando-se a concentração de $500 \mathrm{mg} \mathrm{L}^{-1}$, e pulverizado nas sementes sob o papel germinativo até que se observasse a formação de uma camada homogênea do produto de modo a umedecer 
todo papel. O procedimento para a aplicação do ácido giberélico foi o mesmo adotado no Ethrel.

No teste de germinação, as sementes foram acondicionadas entre folhas de papel germitest (rolo), umedecido com água destilada em quantidade equivalente a 2,5 vezes a massa do substrato seco. $\mathrm{O}$ conjunto foi armazenado em câmara de germinação de Mangelsdorf com temperatura constante de $25{ }^{\circ} \mathrm{C}$ e umidade relativa do ar variando entre $80 \%$ e $85 \%$. As contagens de sementes germinadas foram realizadas semanalmente até o vigésimo oitavo dia, tendo início sete dias após a instalação do teste de germinação.

A determinação do período de avaliação baseou-se em pesquisas anteriores realizadas com a cultura (SOUSA et al., 2008; STENZEL et al., 2003), uma vez que tais critérios não estão definidos nas Regras para Análise de Sementes (BRASIL, 2009).

Foram avaliadas: as variáveis de taxa de germinação (que consistiu na determinação da porcentagem de sementes germinadas), o índice de velocidade de germinação, o tempo médio de germinação, a velocidade média de germinação e o comprimento da raiz primária.

$\mathrm{O}$ índice de velocidade de germinação foi calculado utilizando a seguinte equação: IVG $=\mathrm{G}_{1} / \mathrm{N}_{1}+\mathrm{G}_{2} / \mathrm{N}_{2}+$ $\mathrm{G}_{3} / \mathrm{N}_{3}+\ldots+\mathrm{G}_{\mathrm{n}} / \mathrm{N}_{\mathrm{n}}$, descrita por Maguire (1962); onde " $G$ " representa o número de plântulas normais germinadas a cada dia, dividido pelo número de dias decorridos ("N") entre a semeadura e a germinação.

$\mathrm{O}$ tempo médio de germinação foi obtido através da equação TMG $=\left(\mathrm{G}_{1} \mathrm{~N}_{1}+\mathrm{G}_{2} \mathrm{~N}_{2}+\mathrm{G}_{3} \mathrm{~N}_{3}+\ldots+\mathrm{G}_{\mathrm{n}} \mathrm{N}_{\mathrm{n}}\right) \mathrm{T}$; sendo que " $\mathrm{G}$ " representa o número de plântulas normais germinadas a cada dia, "N" o número de dias decorridos entre a semeadura e a germinação e "T" o número total de sementes germinadas (LABOURIAU, 1983).

Para o cálculo da velocidade média de germinação foi utilizada a fórmula $\mathrm{T}=\left(\mathrm{n}^{\circ}\right.$ de sementes germinadas $\mathrm{x}$ intervalo de avaliação) $/ \mathrm{n}^{\circ}$ de sementes da repetição (LABOURIAU; VALADARES, 1976), enquanto que o comprimento da raiz primária, obtido pela medição das raízes primárias com régua graduada.

Os dados obtidos nos diferentes tratamentos em cada dia de avaliação foram transformados em $\sqrt{ } \mathrm{x}+0,5$ e, após atenderem às pressuposições de normalidade e homocedasticidade, foram submetidos à análise de variância pelo teste $\mathrm{F}$; observada significância as médias foram comparadas pelo teste de Tukey a 5\% de probabilidade para o fator tratamento pré-germinativo não mecânico.

\section{Resultados e Discussão}

A partir da análise de variância constatou-se que houve interação entre os fatores estudados entre as variáveis taxa de germinação e velocidade média de germinação. Enquanto que, para o índice de velocidade de germinação e o tempo médio de germinação houve diferença estatística isoladamente dentre os fatores estudados. Para o comprimento de radícula não foi observada influência dos fatores estudados

Para a taxa de germinação e para a velocidade média de germinação observou-se que o tratamento das sementes com solução contendo GA3 resultou na maior taxa de germinação, na presença de escarificação mecânica (Tabela 1).

Tabela 1. Efeito da utilização tratamentos pré-germinativos não mecânicos em associação a tratamento pré-germinativo mecânico com escarificação mecânica na taxa de germinação e velocidade média de germinação (VMG) das sementes de pinha. Goiânia, GO. 2015

\begin{tabular}{|c|c|c|}
\hline \multirow{2}{*}{ Tratamento } & \multicolumn{2}{|c|}{ Escarificação mecânica } \\
\hline & Ausência & Presença \\
\hline & \multicolumn{2}{|c|}{ Taxa de germinação $(\%)$} \\
\hline \multicolumn{3}{|c|}{ Tratamentos pré-germinativos não mecânicos } \\
\hline Controle & $3,85 \mathrm{aA}$ & $7,69 \mathrm{bA}$ \\
\hline Ethrel (500 $\left.\mathrm{mg} \mathrm{L}^{-1}\right)$ & $0,00 \mathrm{aA}$ & $3,85 \mathrm{bA}$ \\
\hline Água quente $\left(60^{\circ} \mathrm{C} / 1 \mathrm{~min}\right)$ & $0,00 \mathrm{aA}$ & $7,69 \mathrm{bA}$ \\
\hline Ácido giberélico (1000 mg L ${ }^{-1}$ ) & $13,46 \mathrm{aB}$ & $50,00 \mathrm{aA}$ \\
\hline \multirow[t]{2}{*}{ C.V. $(\%)$} & \multicolumn{2}{|c|}{52,39} \\
\hline & \multicolumn{2}{|c|}{ VMG (sementes germinadas por dia) } \\
\hline Controle & $0,02 \mathrm{aA}$ & $0,04 \mathrm{bA}$ \\
\hline Ethrel $\left(500 \mathrm{mgL}^{-1}\right)$ & $0,00 \mathrm{aA}$ & $0,02 \mathrm{bA}$ \\
\hline Água quente $\left(60^{\circ} \mathrm{C} / 1 \mathrm{~min}\right)$ & $0,00 \mathrm{aA}$ & $0,05 \mathrm{bA}$ \\
\hline Ácido giberélico $\left(1000 \mathrm{mgL}^{-1}\right)$ & $0,07 \mathrm{aB}$ & $0,22 \mathrm{aA}$ \\
\hline C.V. $(\%)$ & & \\
\hline
\end{tabular}

Médias seguidas de mesma letra, minúscula nas colunas e maiúsculas nas linhas, não diferem entre si pelo teste de Tukey para o fator tratamentos prégerminativos não mecânicos e pelo teste F para o fator escarificação mecânica $(\mathrm{P}>0,05)$. C.V.: Coeficiente de variação. 
O tratamento das sementes de pinha com ácido giberélico propiciou maiores valores de índice de velocidade de germinação assim como no tempo médio de germinação quando se compara com ethrel (Tabela 2). Da mesma forma, a utilização da escarificação mecânica resultou em melhores valores para estas variáveis

Respostas positivas à superação de dormência em sementes de pinha também foram observadas por Menegazzo et al. (2013) quando utilizando soluções de $\mathrm{GA}_{3}$ a $100 \mathrm{mg} \mathrm{L}^{-1}$ e $250 \mathrm{mg} \mathrm{L}{ }^{-1}$, em sementes não escarificadas de pinha constataram porcentagem de germinação superior ao obtido no presente estudo. A giberelina pode ser responsável pela mobilização das reservas energéticas presentes no endosperma das sementes de várias espécies (TAIZ; ZEIGER, 2013). Isto indica que a aplicação exógena de ácido giberélico pode alterar o metabolismo da semente, incitando um fornecimento prematuro de energia necessária ao desenvolvimento do embrião.

Ao estudarem os efeitos da aplicação de ácido giberélico em sementes de três espécies de anonáceas, Lima-Brito et al. (2006) observaram que a utilização de concentrações variando de 250 a $1000 \quad \mathrm{mg} \mathrm{L}^{-1}$ incrementaram a taxa de germinação e a velocidade de emergência das sementes de pinha em relação ao tratamento controle.

O tratamento das sementes de pinha com ácido giberélico propiciou maiores valores de índice de velocidade de germinação assim como no tempo médio de germinação quando se compara com Ethrel (Tabela 2). Da mesma forma, a utilização da escarificação mecânica resultou em melhores valores para estas variáveis

A maior velocidade de germinação de sementes tratadas com solução contendo $\mathrm{GA}_{3}\left(1000 \mathrm{mg} \mathrm{L} \mathrm{L}^{-1}\right)$ pode estar relacionada ao efeito de enfraquecimento da camada do endosperma que envolve o embrião, desenvolvendo-se forma mais adequada visto que o envoltório não implica em uma barreira física (TAIZ; ZEIGER, 2013).

A escarificação mecânica, por sua vez, também favorece o enfraquecimento do envoltório seminal rígido, tornando-o mais permeável facilitando assim o desenvolvimento do embrião. No entanto, alguns estudos demonstram que em outras espécies de anonácea que contém o mesmo tegumento presente nas sementes de pinha, a absorção de água não é um obstáculo, indicando, desta forma, que a dormência destas sementes é causada por fatores endógenos (WAGNER JÚNIOR et al., 2006).

Os baixos índices obtidos no presente estudo podem estar relacionados à presença de um embrião rudimentar de desenvolvimento lento - característica das sementes de anonáceas - que na maioria dos casos não está totalmente diferenciado, mesmo quando os frutos se encontram maduros. O embrião permanece no mesmo estado mesmo depois de coletadas as sementes (OLIVEIRA et al., 2010).

Em conformidade com demais trabalhos da literatura, a utilização de $\mathrm{GA}_{3}$ na superação da dormência de sementes de espécies do gênero Annona consta como método de maior eficácia. Porém, no presente estudo demonstra-se que o efeito do ácido giberélico pode ser potencializado quando utilizado conjuntamente com a técnica de escarificação mecânica das sementes.

\section{Conclusões}

Os tratamentos pré-germinativos das sementes de pinha com ácido giberélico em associação com escarificação mecânica é o método indicado para a superação da dormência desta espécie.

Tabela 2. Efeito da utilização de tratamentos pré-germinativos não mecânicos em associação a tratamento pré-germinativo mecânico com escarificação mecânica no índice de velocidade de germinação e na taxa média de germinação das sementes de pinha. Goiânia, GO. 2015

\begin{tabular}{lcc}
\hline \multicolumn{1}{c}{ Tratamento } & & Variável \\
\cline { 2 - 3 } & & IVG \\
\hline Tratamentos pré-germinativos não mecânicos & $0,02 \mathrm{~b}$ & $7,00 \mathrm{ab}$ \\
\hline Controle & $0,04 \mathrm{~b}$ & $2,19 \mathrm{~b}$ \\
Ethrel (500 $\left.\mathrm{mg} \mathrm{L}^{-1}\right)$ & $0,06 \mathrm{~b}$ & $3,94 \mathrm{ab}$ \\
Água quente $\left(60^{\circ} \mathrm{C} / 1 \mathrm{~min}\right)$ & $0,32 \mathrm{a}$ & $12,18 \mathrm{a}$ \\
Ácido giberélico $\left(1000 \mathrm{mg} \mathrm{L}^{-1}\right)$ & & $3,14 \mathrm{~b}$ \\
\hline Escarificação mecânica & $0,05 \mathrm{~b}$ & $9,51 \mathrm{a}$ \\
\hline Ausência & $0,16 \mathrm{a}$ & 71,48 \\
Presença & 7,35 & $\mathrm{a}$ \\
\hline C.V. $(\%)$ & & \\
\hline
\end{tabular}

Médias seguidas de mesma letra não diferem entre si pelo teste de Tukey para o fator tratamentos pré-germinativos não mecânicos e pelo teste $\mathrm{F}$ para o fator escarificação mecânica $(\mathrm{P}>0,05)$. C.V.: Coeficiente de variação. 


\section{Referências Bibliográficas}

BRASIL MAPA. MINISTÉRIO DA AGRICULTURA, PECUÁRIA E ABASTECIMENTO. Regras para análise de sementes. Brasília - DF: Secretaria de Defesa Agropecuária e Coordenação Geral de Apoio Laboratorial, 2009. 395p.

CAMPOS, L. F. C.; ABREU, C. M. D.; GUIMARÃES, R. N.; SELEGUINI, A. Scarification and gibberellic acid on emergence and seedling growth of Biriba. Ciência Rural, Santa Maria-RS v. 45, n. 10, p. 1748-1754, 2015.

FERREIRA, M. G. R.; SANTOS, M. R. A.; SILVA, E. O.; GONÇALVES, E. P.; ALVES, E. U.; BRUNO, R. L. A. Superação de dormência em sementes de biribá (Rollinia mucosa (Jacq.) Baill). Revista Brasileira de Sementes, Londrina-PR, v. 31, n. 4, p. 95-99, 2009.

GALINDO, E. A.; ALVES, E. U.; SILVA, K. B.; BARROZO, L. M.; MOURA, S. S. S. Germinação e vigor de sementes de Crataeva tapia $\mathrm{L}$. em diferentes temperaturas e regimes de luz. Revista Ciência Agronômica, Fortaleza-CE, v. 43 , n. 1, p. 138-145, 2012.

LABOURIAU, L. F. G. A Germinação de sementes. Washington: Organização dos Estados Americanos, 1983. $174 \mathrm{p}$.

LABOURIAU, L. F. G.; VALADARES, M.E.B. On the germination of seeds Calotropis procera (Ait.) Ait.f. Anais da Academia Brasileira de Ciências, Rio de Janeiro-RJ. v.48, n.2, p.263-284, 1976.

LIMA-BRITO, A.; CAMPOS, V. C. A.; SANTANA, J. R. F.; DORNELLES, A. L. C. Efeito do ácido giberélico (GA3) na emergência de plântulas de Annona crassiflora Mart., Annona squamosa L. e Annona muricata L. Magistra, Cruz das Almas-BA, v. 18, n. 1, p. 27-33, 2006.

MAGUIRE, J. D. Speed of germination aid in selection and evaluation for seedling emergence and vigor. Crop Science, Madison-WI, v. 2, n. 2, p.176-177, 1962.

MELO, A. P. C.; SELEGUINI, A.; CASTRO, M. N.; ANDRADE MEIRA, F.; SILVA GONZAGA, J. M.; HAGA, K. I. Superação de dormência de sementes e crescimento inicial de plântulas de umbuzeiro. Semina: Ciências Agrárias, Londrina-PR v. 33, n. 4, p. 1343-1350, 2012.

MENEGAZZO, M. L.; KULCZYNSK, S. M.; OLIVEIRA, A. C.; SILVA, E. A. Produção de mudas de pinha em diferentes recipientes utilizando métodos de superação de dormência em sementes. Revista Agrarian, Dourados-MS, v. 6, n. 20 , p. 121-129, 2013.

NETO, A. F.; DANTAS, B. F.; ALMEIDA, F. A. C.; LIMA, M. S.; SILVA, F. F. S. Influência da embalagem e do local de armazenamento na qualidade fisiológica de sementes de abóbora 'jacarezinho' (Curcubita moschata Duch). Revista Engenharia na Agricultura, Viçosa-MG, v. 22, n. 4, p. 294305, 2014.
OLIVEIRA, M. C.; FERREIRA, G.; GUIMARÃES, V. F.; DIAS, G. B. Germinação de sementes de atemoia (Annona cherimola Mill. x A. squamosa L.) cv 'Gefner' submetidas a tratamentos com ácido Giberélico (GA3) e ethephon. Revista Brasileira de Fruticultura, Jaboticabal-SP, v.32, n.2, p. 544-554, 2010.

SÃO JOSÉ, A. R.; PIRES, M. M.; FREITAS, A. L. G. E.; RIBEIRO, D. P.; PEREZ, L. A. A. Atualidades e perspectivas das Anonáceas no mundo. Revista Brasileira de Fruticultura, Jaboticabal-SP, v. 36, n. especial, p. 86-93, 2014.

SCALOPPI JUNIOR, E. J.; MARTINS, A. B. G. Estaquia em Anonas. Revista Brasileira de Fruticultura, Jaboticabal-SP, v.36, n. especial, p. 147-156, 2014.

SILVA, A V. C.; ANDRADE, D. G.; YAGUIU, P.; CARNELOSSI, M. A. G.; MUNIZ, E. N.; NARAIN, N. Uso de embalagens e refrigeração na conservação de atemóia. Ciência e Tecnologia de Alimentos, Campinas-SP, v. 29, n. 2, p. 300-304, 2009.

SILVA, P. E. M.; SANTIAGO, E. F.; DALOSO, D. M.; SILVA, E. M.; SILVA, J. O. Quebra de dormência em sementes de Sesbania virgata (Cav.) Pers. Idesia, AricaChile, v. 29, n. 2, p. 39-45, 2011.

BRAGA SOBRINHO, R. Produção integrada de Anonáceas no Brasil. Revista Brasileira de Fruticultura, JaboticabalSP, v. 36 n. especial, p. 102-107, 2014.

SOUSA, S. A.; DANTAS, A. C. V. L.; PELACANI, C. R.; VIEIRA, E. L.; LEDO, C. A. S. Superação da dormência em sementes de pinha. Caatinga, Mossoró-RN, v. 21, n. 4, p. 118-121, 2008.

STENZEL, N. M. C.; MURATA, I. M.; NEVES, C. S. V. J. Superação da dormência em sementes de atemóia e fruta-doconde. Revista Brasileira de Fruticultura, Jaboticabal-SP, v. 25 , n. 2 , p. $305-308,2003$.

TAIZ, L.; ZEIGER, E. Fisiologia vegetal. 5. ed. Porto Alegre: ArtMed, 2013. 954p.

WAGNER JÚNIOR, A.; PIMENTEL, L. D.; NEGREIROS, J. R. S.; ERES, C. R. L.; ALEXANDRE, R. S.; DINIZ, E. R.; BRUCKNER, C. H. Influência do tempo de embebição em água sobre a dormência de sementes de pinha (Annona squamosa L.). Ceres, Viçosa-MG, v. 53, n. 307, p. 317-332, 2006. 